\title{
CVD diamond/substrate interface FIB preparation of cutting tools
}

\author{
S.B. Peripolli", F.A. Almeida ${ }^{* *}$, L.S. Gomes ${ }^{*}$, F.J. Oliveira ${ }^{* *}, \underline{\text { R.F. Silva }}^{* *}$ and C.A. Achete $^{* * * * * *}$ \\ *Instituto Nacional de Metrologia, Normalização e Qualidade Industrial, Divisão de Metrologia de \\ Materiais - DIMAT, Av. Nossa Senhora das Graças 50, Xerém, Duque de Caxias, RJ - CEP 25250- \\ 020, Brazil \\ ** Ceramics Eng. Dept., CICECO, Aveiro University, 3810-193 Aveiro, Portugal \\ ${ }^{* * *}$ Universidade Federal do Rio de Janeiro, Engenharia Metalúrgica e de Materiais, Cx. Postal \\ 68505, Rio de Janeiro, RJ, CEP 21945-970, Brazil \\ rsilva@ua.pt
}

CVD diamond coated cutting tools are used for machining of abrasive and hard materials such as Al-Si alloys and tungsten carbide [1]. The knowledge of the mechanisms governing the diamond/substrate interfacial strength is crucial in cutting tools design. The most adequate substrate material for maximizing the adhesion of diamond films is the silicon nitride $\left(\mathrm{Si}_{3} \mathrm{~N}_{4}\right)$ ceramic that possesses a thermal expansion coefficient similar to that of diamond. Buchkremer-Hermanns and co-workers [2] consider the formation of a $\mathrm{SiC}$ interlayer between diamond and $\mathrm{Si}_{3} \mathrm{~N}_{4}$, which may favour chemical bonding to diamond, although they could not detect it by glazing incidence X-Ray diffraction. They believed that insufficient detection sensitivity for very thin films, texture effects or presence of amorphous layers are possible reasons. In the case of TiN substrates, a graded interlayer of amorphous TiCN of only $8 \AA$ was suggested by Contreras, as observed by HRTEM images and EDS measurements [3]. Due to the difficulty in the detection of such layers, which can be in the order of a few angstrons, a definite evidence of their nature is yet to be demonstrated.

The present work is devoted to the use of the focused ion beam (FIB) technique for extracting ultrathin specimens from CVD diamond coated cutting tools, ready for HRTEM studies of the diamond $/ \mathrm{Si}_{3} \mathrm{~N}_{4}$ interface. The use of FIB open a new route for preserving interfaces between dissimilar materials, which is particularly relevant in the case of extremely hard CVD diamond coatings. The time spent to the preparation of TEM-ready foil by FIB technique is significantly lower than the conventional cutting, grinding, polishing and argon ion milling [4], and proved to be an efficient way to the in-situ preparation of hard materials for HRTEM investigation. As FIB is a powerful precision etching technique, it has also been used to micromachine 3D-structured diamond single-crystal devices for optical waveguiding with submicron resolution [5].

Round $\mathrm{Si}_{3} \mathrm{~N}_{4}$ cutting inserts were produced by powder technology and diamond coated in a hot filament chemical vapour deposition (HFCVD) reactor to a final film thickness of about $30 \mu \mathrm{m}$, according to the conditions established elsewhere [1]. The dual-beam FIB workstation (FEI Nova Nanolab 600) was used for the HRTEM sample preparation. Opposing trenches (Fig. 1.a) were milled out leaving approximately $20 \mu \mathrm{m}$ in length by $40 \mu \mathrm{m}$ in depth, with an average thickness of 1-2 $\mu \mathrm{m}$ (Fig. 1.b). The section was then welded to the micro-manipulator, extracted from the sample (Fig. 1.c), and fixed to a TEM grid post. Final thinning down to $20 \mathrm{~nm}$ thickness was done using low incident angles and low $\mathrm{Ga}$ ion current, allowing an optimal preservation of the diamond/substrate interface as shown in the TEM micrograph (Fig. 1.d). The study of the chemical 
and cristallography nature of the interface will be further performed in a transmission electron microscopy operating at $300 \mathrm{kV}$ coupled with EDS detector.

\section{References}

[1] F.A. Almeida, M. Amaral, F.J. Oliveira, R.F. Silva, Diam. Relat. Mater. 15 (2006) 2029.

[2] H. Buchkremer-Hermanns, H. Ren, G. Kohlschein, H. Weiss, Surf. Coat. Technol. 98 (1998) 1038.

[3] O. Contreras, G.A. Hirata, M. Avalos-Borja, Appl. Surf. Sci. 158 (2000) 236.

[4] L.A. Gianuzzi, J.L. Drown, S.R. Brown, R.B. Irwin, F.A. Stevie, Microsc. Res. Techn. 41 (1998) 285.

[5] P. Olivero, S. Rubanov, P. Reichart, S. Huntington, B. Gibson, J. Salzman, S. Prawer, D.N. Jamieson, Microsc. Microanal. 11 (2005) 856.

F.A. Almeida acknowledges FCT for a postdoctoral grant (SFRH/BPD/34869/2007).
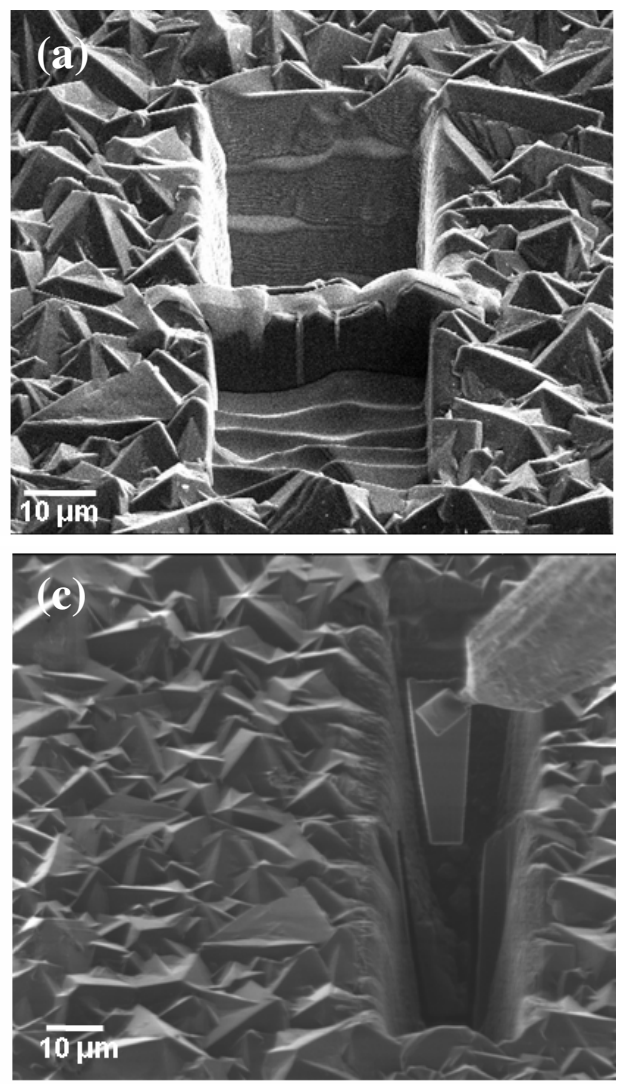
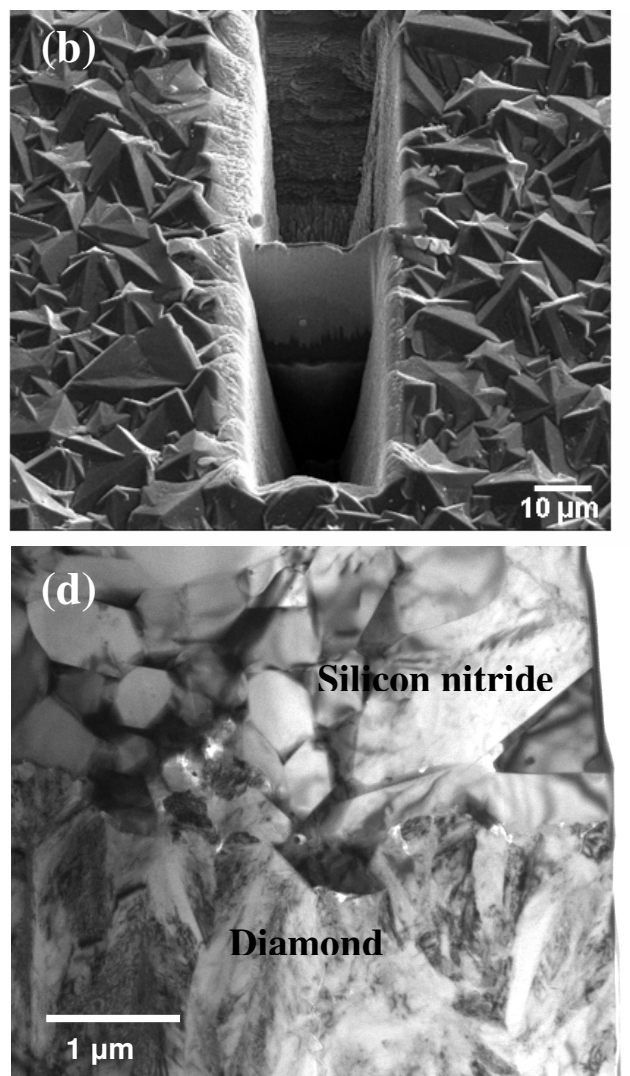

Fig 1. SEM micrographs of milled out trenches (a,b), extraction of diamond/ $\mathrm{Si}_{3} \mathrm{~N}_{4}$ section (c). TEM micrograph of the diamond/ $\mathrm{Si}_{3} \mathrm{~N}_{4}$ interface preserved by FIB preparation (D). 